\section{A New Anaesthetic Technique for Slugs}

During recent studies on the in vitro culture of organs of the Grey Field Slug, Agriolimax reticulatus, it was found necessary to use anaesthesia. Since organs were to be explanted from these anaesthetized slugs, it was necessary that the anaesthetic to be used should give $100 \%$ recovery and it would also be advantageous if the anaesthetic left no residue in the animals' tissues.

A survey was made of the methods for anaesthetizing and narcotizing gastropods ${ }^{1}$. The methods which were used for slugs gave inconsistent recovery rates varying from $0.92 \%$, and often involved the use of complex chemicals.

Since carbon dioxide is widely used as an anaesthetic, especially with insects, it was decided to study its effect as an anaesthetic for slugs. Little mention is made in the literature of the use of carbon dioxide as an anaesthetic for gastropods. It has been used in conjunction with Sevin (1-naphthyl N-methyl-carbamate; Union Carbide) ${ }^{2}$ to relax muricids and also to relax Nucella lapillus prior to fixation ${ }^{1}$. Carbon dioxide has been used in conjunction with Nembutal and MS 222 (Sandoz: meta-aminobenzoic acid ethyl ester methansulphonate) ${ }^{3}$ as an anaesthetic for Lymnea stagnalis. Recently ${ }^{4}$ gaseous carbon dioxide has been used for anaesthetizing slugs but no method is described.

A plastic container, $6 \mathrm{~cm}$ deep with an outlet in the base, was used as the anaesthetic chamber. A layer of cotton wool, about $3 \mathrm{~cm}$ thick, was placed in the bottom of the container and moist filter paper placed upon this. Gaseous carbon dioxide, saturated with water, was passed into the chamber via the basal inlet. The slug was placed upon this moist filter paper and a perforated lid placed on the plastic container. The slug usually remained fairly inactive and the time taken for it to succumb was very variable, sometimes in excess of $1 \mathrm{~h}$.

Using the same chamber, but with no basal inlet, this technique was modified for use with solid carbon dioxide. Crushed solid carbon dioxide (Drikold, I.C.I.) was placed under the cotton wool, in a layer $1 \mathrm{~cm}$ deep, and the gas given off by this was used as the anaesthetic. When the slugs were placed in this chamber they were very active and secreted mucus, but not excessively. They moved about 3 times their length before succumbing to the effects of the anaesthetic. When anaesthetized the animals were invariably in a fully extended state, often with the penial sac everted.

Using this technique anaesthesia is rapid and, even after $5 \mathrm{~min}$, sufficient for minor operations. $10-15 \mathrm{~min}$ has been shown to be the best exposure time. Strong mechanical stimulation of the anterior end of the slug during the first $2-3 \mathrm{~min}$ after removal from the chamber produces no response. The slugs slowly recover from the anaesthetic and appear normal after 20-30 min. Extending the time in the anaesthetic beyond 15 min does not delay the animals recovery time to any extent. However operating time can be extended indefinitely by working in an atmosphere of carbon dioxide. Recovery is $100 \%$ unless the exposure to the carbon dioxide is well in excess of $60 \mathrm{~min}$.

This anaesthetic technique has been used in this laboratory for the past 2 years. During this time it has been found to be extremely teliable ${ }^{5}$.

Résumé. On a étudjé l'effet anesthésique de l'anhydride carbonique sur les limaces. La technique décrite permet une anesthésie totale pendant une heure avec une guérison de $100 \%$.

T. G. BAILEY

Department of Zoology, University College of North Wales, Bangor (North Wales, U.K.), 7 May 1969.

1 N. W. Runham, K. Isarankura and B. J. Smith, Malacologia $2,231(1965)$.

2 M. R. Carriker and J. W. Blake, Nautilus 73, 16 (1959).

3 J. Lever, J. C. Jager and A. Westerveld, Malacologia 1, 331 (1964).

4 I. F. Henderson, Ann. appl. Biol. 63, 167 (1969).

5 I thank Professor J. M. Dond for the provision of laboratory facilities and Dr. N. W. Runham for criticizing the manuscript. During the course of this work I have been in tenure of a Scientific Research Council Postgraduate Award.

\section{Observation of Nerve Fibers in Incident Light}

In previous publications we have described the development and application of a new type of microscope employing tandem scanning 1,2 . This microscope was designed expressly for in vivo observation of brain cells. A major limitation in the first versions of this microscope was the great light loss entailed by the scanning system, resulting in such low image brightnesses that the only satisfactory source for observation of nervous tissue was the reflected light of the sun. Recently one of us (M.D.E.) designed a scanning system compatible with the original microscope, but having a much greater coefficient of light transmission, thus making possible observation of unstained nervous tissue with a conventional artificial light source.
The scanning system is based on the wheel illustrated in Figure 1; silvered except for 800 symmetrically placed radial slits of $40 \mu$ width. Light from a 200 -watt mercury short arc lamp (PEK) was focused on the wheel which was rotated at $200 \mathrm{rpm}$. The radially symmetrical slits on opposite sides of the wheel were made optically congruent by inverting prism systems as in the original tandem scanning microscope ${ }^{2}$.

1 M. D. Egger and M. Petráñ, Science 157, 305 (1967).

2 M. Petrán̆, M. Hadravskí, M. D. Egger and R. Galambos, J. Opt. Soc. Am. 58, 661 (1968). 